\title{
GRAPHICAL LEAST SQUARES METHOD AND GAUSS
}

ŚLACKI

PRZEGLĄD

STATYSTYCZNY

Nr 18(24)

\section{Oscar Sheynin}

Honorary member of the Royal Statistical Society, London e-mail: oscar.sheynin@googlemail.com; website: www.sheynin.de

\section{(C) 2020 Oscar Sheynin}

This work is licensed under the Creative Commons Attribution-ShareAlike 4.0 International License. To view a copy of this license, visit http://creativecommons.org/licenses/by-sa/4.0/

Quote as: Sheynin, O. (2020). Graphical least squares method and Gauss. Śląski Przegląd Statystyczny, 18(24).

DOI: $10.15611 /$ sps.2020.18.24

JEL Classification: D12; C13; C25

Tutubalin (1973, section 2.4, p. 27) described the result of an experiment. Sixteen mathematicians and engineers smoothed over an empirical broken line by the naked eye. The results were quite comparable in precision with the method of least squares (MLSq). This simple procedure seems to be barely known and should be borne in mind.

Enter Gauss! He could have known and applied it before 1805, i.e. before Legendre published his discovery of (the qualitatively recommended) MLSq. Some commentators question Gauss' actual (although not formal) priority, and this author (Sheynin, 2017, § 9A.1.4) noted that there had existed many instances in which Gauss could have well applied his innovation, at least for preliminary trial calculations or shortcuts, before the publication by Legendre. For him, the MLSq was not a cut-and-dried procedure, and weighing the observations as well as the possible mistakes in his calculations could have hampered justification. The author also mentioned friends and colleagues whom Gauss had notified about the MLSq, again before 1805 .

Now, in addition, this author thinks that in some instances Gauss could have applied that described graphical procedure with no-one being the wiser. Indeed (Kronecker, 1901, p. 42) wrote:

After proving his theorems, Gauss always got rid of all traces of his train of thoughts which led him to his results.

May (1972) voiced a similar opinion.

Now let us think seriously before deciding that Gauss had not known that ..., had not arrived at ..., did not see that ..., and he likely thought that 
this graphical least-squares procedure was good enough. But how about estimating the precision of such procedures? Anyone was able to achieve this goal informally but fairly well by repeating several times the nakedeye method and Tutubalin's experiment, for one, provided this possibility.

\section{References}

Kronecker L. (1901), Vorlesungen über Zahlentheorie, Bd. 1. Leipzig. May K.O. (1972), Gauss. Dict. Scient. Biogr., vol. 5, pp. 298-315. Scribner, New York. Sheynin O. (2017), Theory of Probability. Historical Essay. Berlin. Also on my website www.sheynin.de dowloadable file 10.

Tutubalin V.N. (1973), Statisticheskaia Obrabotka Riadov Nabliudeniy (Statistical Treatment of Series of Observations). Znanie, Moscow. 